\title{
Nongenetic effects and genetic parameters for length of productive life of Holstein cows in Hokkaido, Japan
}

\author{
Y. Terawaki*1 and V. Ducrocq† \\ ${ }^{*}$ Rakuno Gakuen University Dairy Science Institute, 069-8501 Ebetsu, Japan \\ †UR337, Département de Génétique Animale, Institut National de la Recherche Agronomique, 78352 Jouy en Josas, France
}

\begin{abstract}
Records of Holstein dairy cows in Hokkaido, Japan, were used to study the effects of environmental factors on length of productive life and to estimate genetic parameters for length of productive life. Each record was assigned to 1 of 3 data sets depending on the percentage of type-scored cows in the herd. This percentage was considered to partly reflect the management policy in each herd, in particular regarding culling. The A, B, and $\mathrm{C}$ data sets consisted of herds with none, less than $60 \%$, and more than $60 \%$ of type-scored cows, respectively, and included $158,719,787,598$, and 131,499 records, respectively. Analyses of length of productive life were separately carried out on each data set using the Survival Kit software (Version 5.0). Nonparametric hazards estimates and the shape parameters of the baseline Weibull distribution differed between the 3 data sets. A cow having a sire originating from the United States or Canada had a relatively lower risk of being culled than a cow having Japanese sire in data set C. However, in data set A, a cow having a Canadian sire had a higher relative risk than a cow having a Japanese sire. The herd-year variance for data set A was about twice as large as for data set C. In contrast, the sire variance for data set A was about $40 \%$ of the one for data set C. As a result, heritability varied across data sets from 0.046 to 0.134 . The results of this study suggest that it is important to consider factors related to herd management policy, such as the percentage of type-scored cows, in genetic analyses on length of productive life of Holstein cows in Hokkaido, Japan.
\end{abstract}

Key words: nongenetic effect, genetic parameter, length of productive life, Holstein

\section{INTRODUCTION}

The average lactation number of Holstein cows in Hokkaido, Japan, has been decreasing in recent years

Received March 24, 2008.

Accepted December 12, 2008.

${ }^{1}$ Corresponding author: terawaki@rakuno.ac.jp
(Okada, 2001) and was 2.7 in 2006 (LIAJ Inc., 2006). Replacing cows at the end of their sixth lactation was found to be the most profitable scenario in a Canadian study (Mason, 2004). This study indicated that the economic differences were minor between the third and the tenth lactation, and the loss in profit was very significant for cows with only 1 or 2 lactations. The extension of length of productive life (LPL) also increases profit in Holstein herds in Japan, even though economic conditions in Japan are not the same as in Canada.

To prevent market surpluses and price instability, the Japanese dairy industry has been regulated since 1966 through a mixed system with a production ceiling at government level and voluntary planning at dairy cooperatives and farmers level (Japan Dairy Council, 2007). Dairy farmers had to throw away milk surpluses due to overproduction in 2006, and recently, a decrease in reproductive performance and an increase of incidence of diseases has been observed in Holstein cows in Japan (LIAJ Inc., 2006). Thus, strategies other than increase of milk production in a dairy cow may be needed for increasing net income of dairy farms in Japan. A possible alternative is to reduce production costs. In Japan, replacement costs of heifers represent a large part of total production costs. Therefore, LPL influences herd profit and genetic improvement of LPL is becoming an important aim in Japan. VanRaden (2004) reported transition of the selection index for dairy cattle in the United States and Miglior et al. (2005) compared several selection indices for Holstein cattle in various countries. Recently, in many countries, traits other than production have been included in selection index. Particularly, traits related to fertility and reproduction have received strong emphasis in Denmark, France, the United States, and Israel (Miglior et al., 2005). Moreover, traits representing longevity have been included in some countries, particularly in Europe (VanRaden, 2004; Miglior et al., 2005).

Many studies about the longevity of Holstein cows have been reported in several countries (Röxström et al., 2003; Ducrocq, 2005; Sewalem et al., 2005; GarciaPeniche et al., 2006; Terawaki et al., 2006; Chirinos et al., 2007). Longevity of Holstein cows appears to be 
Table 1. Descriptive statistics of records in 3 data sets

\begin{tabular}{lccc}
\hline & \multicolumn{3}{c}{ Data set } \\
\cline { 2 - 4 } Item & $\mathrm{A}$ & $\mathrm{B}$ & $\mathrm{C}$ \\
\hline Number (\%) of records & 158,719 & 787,598 & 131,499 \\
& $(14.7)$ & $(73.1)$ & $(12.2)$ \\
Cows with type score (\%) & 0.0 & 18.6 & 77.4 \\
Number (\%) of herds & 1,915 & 5,271 & 871 \\
& $(23.8)$ & $(65.4)$ & $(10.8)$ \\
Average number of records per herd & 82.9 & 149.4 & 151.0 \\
Right-censored records (\%) & 14.3 & 25.9 & 27.7 \\
Average censoring time (d) & $1,080.5$ & $1,004.9$ & $1,040.1$ \\
Uncensored records (\%) & 85.7 & 74.1 & 72.3 \\
Average failure time (d) & $1,100.2$ & $1,159.0$ & $1,220.3$ \\
\hline
\end{tabular}

influenced by the herd management policy (Buenger et al., 2001; Larroque and Ducrocq, 2001; Vukasinovic et al., 2001). Terawaki et al. (2006) recently reported that the existence of a type score for a cow and the origin of its sire significantly influenced its hazard of being culled in Hokkaido. This study was performed using a data set that only included herds in which more than $60 \%$ of cows had a type score. The percentage of cows with a type score in a herd is considered as a criterion that reflects the herd's breeding goals and management policy. For an accurate estimation of genetic parameters of LPL, it is important to assess the importance of potential nongenetic effects on longevity of Holstein cows in a broader range of herds in Hokkaido. The objective of this study was to estimate the effects of nongenetic factors on LPL and genetic parameters for LPL in herds with different percentages of type-scored cows by survival analysis techniques.

\section{MATERIALS AND METHODS}

This study used data from the Hokkaido Dairy Milk Recording and Testing Association. The data included information on production, calving, reproduction, reason for culling, etc., from which LPL records were derived. The observation period was from January 1, 1984 to December 31, 1999. Records of cows still alive at the end of the observation period were considered as censored at December 31, 1999. Also, records of cows sold to other herds for dairy purposes were considered as censored at date of sale. Length of productive life (longevity) was defined as the number of days from first calving to culling or censoring date. Cows having a first calving before January 1984 were excluded from the analysis. After editing, 1,077,816 records were available in total. Depending on the proportion of cows having a type score in a herd, records were divided into 3 data sets (A, B, and C, see Table 1). Data set A included the records in herds for which none of the cows were scored for type. The cows reared in herds for which more than $60 \%$ of cows had a type score belonged to data set C. All other cows were included in data set B and average percentage of type-scored cows was $18.6 \%$.

Terawaki et al. (2006) presented a comparison of different models for survival analysis of LPL of Holstein cows in Hokkaido and determined the most suitable model to be adopted. Based on those results, the analysis of LPL was performed using the following survival model with piecewise Weibull baselines:

$$
\begin{aligned}
\mathrm{h}(\mathrm{t}) & =\mathrm{h}_{0, \mathrm{n}}(\tau) \exp \left[\mathrm{HY}_{i}\left(\mathrm{t}^{\prime}\right)+\mathrm{Y}_{j}\left(\mathrm{t}^{\prime}\right)+\operatorname{MILK}_{k}\left(\mathrm{t}^{\prime \prime}\right)\right. \\
& \left.+\mathrm{SIZE}_{l}\left(\mathrm{t}^{\prime}\right)+\mathrm{MP}_{m}\left(\mathrm{t}^{\prime \prime}\right)+\mathrm{SC}_{o}+\mathrm{TS}_{p}\right]
\end{aligned}
$$

where $\mathrm{h}(\mathrm{t})$ is the hazard function of the cow; $\mathrm{t}$ is the number of days after its first calving; $h_{0, n}(\tau)$ is the Weibull baseline for the nth subclass of parity by stage of lactation; $\tau$ denotes the number of days between the most recent calving and current time t; $\mathrm{HY}_{i}\left(\mathrm{t}^{\prime}\right)$ is the effect of the $i$ th herd-year interaction, assumed to follow a log-gamma distribution with dispersion parameter $\gamma$; $\mathrm{Y}_{j}(\mathrm{t}$ ') is the time-dependent fixed effect of the $j$ th year $(1984,1985, \ldots ., 1999)$; and $\operatorname{MILK}_{k}(\mathrm{t}$ ") is the timedependent fixed effect of the $k$ th within-herd class of $305-d$ milk yield. Each record of milk yield was coded from 1 to 7 based on within-herd $\times$ year classes. Number of records of score 1 (the lowest milk yield) were the smallest in 3 data sets and the percentage of records was 3.0 to $5.1 \%$; $\mathrm{SIZE}_{l}\left(\mathrm{t}^{\prime}\right)$ is the time-dependent fixed effect of the $l$ th class of variation in herd size. The 5 classes of the SIZE effect reflected the change in herd size between the previous year and the current one (class 1 is $<-15 \%, 2$ is $-15 \%$ to $-5 \%, 3$ is $>-5 \%$ to $<+5 \%, 4$ is $+5 \%$ to $+15 \%, 5$ is $>+15 \%$ ). Class 1 (data sets $\mathrm{B}$ and $\mathrm{C}$ ) and class 2 (data set A) had the smallest proportion of records, and these percentages were 4.6, 3.4 , and $10.0 \% ; \mathrm{MP}_{m}\left(\mathrm{t}^{\prime \prime}\right)$ is the time-dependent fixed effect of the $m$ th interaction between within-herd class 

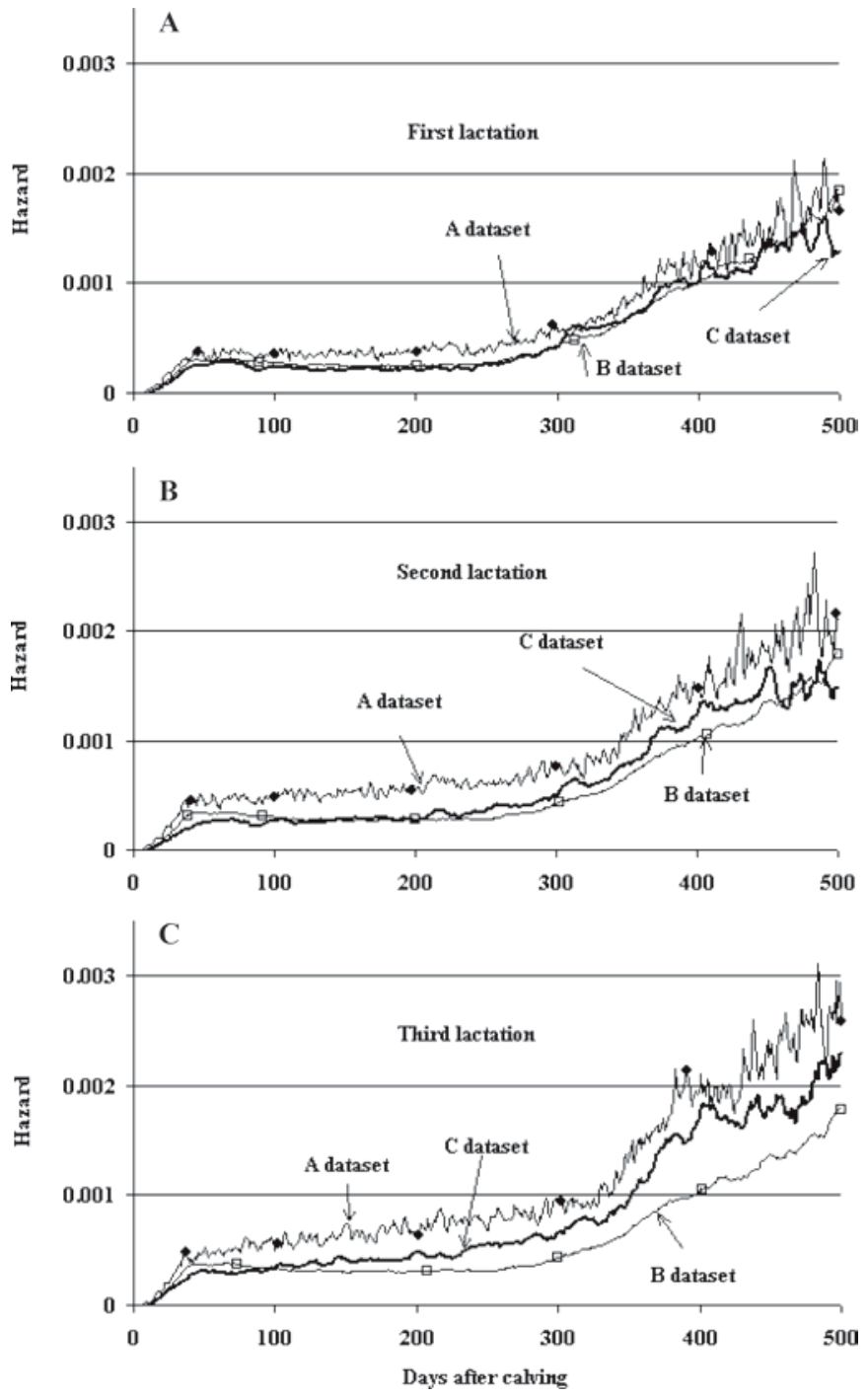

Figure 1. Hazards using the Kaplan-Meier method by lactation for the 3 data sets. Cut points used to define lactation stage: 60,250 , and 350 DIM. A data set $(-\bullet-)$, B data set $(-\square-)$, and $\mathrm{C}$ data set $(-)$.

of 305-d milk yield $(1,2, \ldots, 7)$ and parity $(1,2, \ldots$, $6=<) ; \mathrm{SC}_{o}$ is the time-independent fixed effect of the oth group of country origin of the cow's sire $(1=$ Japan; $2=\mathrm{US} ; 3=$ Canada); and $\mathrm{TS}_{p}$ is the time-independent fixed effect of presence of type scores for this cow $(1=$ presence; 2 = absence). See Terawaki et al. (2006) for details. The factor $\mathrm{TS}_{p}$ was excluded from the model when analyzing data set $\mathrm{A}$, for which none of the cows had a type score. For estimating genetic parameters, the data sets were edited for herds having at least 30 records and sires having at least 20 daughters regardless of end code of record, and a sire effect was added to the model. Sire effects were assumed to be independent and to follow a normal distribution. In total, 95,718, 385,237 , and 117,182 records were used for estimating heritability, and 496, 952, and 568 sires were included in the pedigree file of data sets A, B, and C, respectively. All computations were carried out separately on each data set using the Survival Kit (version 5.0) software (Ducrocq and Sölkner, 1998).

\section{RESULTS}

Table 1 shows basic statistics for the 3 data sets. Data set B included about $73 \%$ of the total number of records over the 3 data sets and $65 \%$ of the total number of herds. Data set $\mathrm{C}$ included the smallest number of records and the smallest number of herds. However, data set $\mathrm{C}$ had the largest average number of records per herd. Data set A consisted of a large number of small herds. The proportion of right-censored records of data set C was low (27.7\%) and similar to Terawaki et al. (2006). The corresponding proportions (14.3 and $25.9 \%$ ) in data sets A and B were even lower than in data set $\mathrm{C}$. The average failure time was the longest $(1,220 \mathrm{~d})$ in data set $\mathrm{C}$ and the shortest $(1,100 \mathrm{~d})$ in data set A.

Figure 1 shows the nonparametric (Kaplan-Meier) hazards estimated by parity for the 3 data sets. The hazards showed similar patterns regardless of parities and data sets. The hazard rapidly increased after calving until 30 or $40 \mathrm{~d}$. Then the hazard was relatively stable until about $280 \mathrm{~d}$ after calving. Later, the hazard showed an abrupt increase. Differences among the hazards of the 3 data sets got larger as parity advanced.

Figure 2 shows the estimates of the Weibull shape parameter $\rho$ by lactation stage and parity for the 3 data sets. Values of $\rho$ less than 1 indicate that risk decreases with time, whereas $\rho$ values larger than 1 reflect an increase in risk over time. The larger $\rho$ is, the faster the increase. The changes of the $\rho$ values within parity showed similar patterns in the 3 data sets: the $\rho$ values decreased for the second lactation stage $(60$ to 250 DIM), then dramatically increased for the third lactation stage (250 to 350 DIM), and again decreased for the fourth stage ( $>350$ DIM). Changes observed from the first to the third parity were similar in the 3 data sets. The amplitude of these changes was largest in data set $\mathrm{C}$ (Figure $2 \mathrm{C}$ ) and smallest in data set A (Figure 2A). These changes decreased with increasing parity. The $\rho$ values in the second stage became larger as parity number increased (except for the sixth parity). This reflected a larger hazard in later parities for the period from 60 to $250 \mathrm{~d}$ after calving. In contrast, the later the parity, the smaller the $\rho$ values for the third stage. Indeed, the hazard in first parity showed the most abrupt increase between 250 and $350 \mathrm{~d}$ after calving. The $\rho$ value for this late stage was largest for data set $\mathrm{C}$ (Figure $2 \mathrm{C}$ ) and smallest for data set A (Figure 2A). 
A
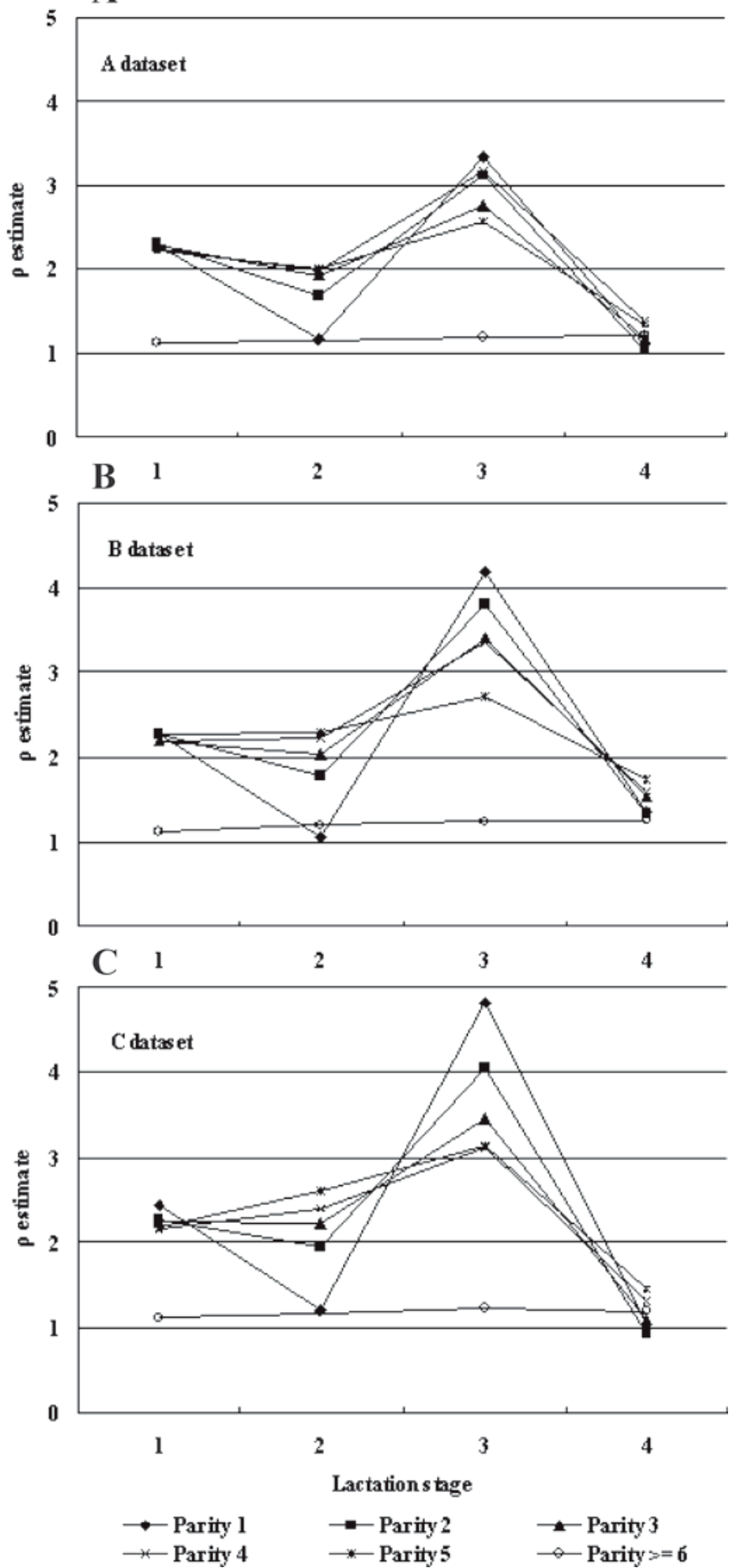

Figure 2. Weibull parameter $(\rho)$ estimates by lactation stage and parity for 3 data sets. Cut points used to define lactation stage: 60, 250, and 350 DIM.
Figure 3 shows the relative risk ratios for milk yield and country of origin of the cow's sire. These estimates were obtained independently for the 3 data sets, and therefore, the reference categories in each data set are not directly comparable because they correspond to different animals. However, the change in risk between a particular class of animals and the reference class can be used to assess differences in culling practices between data sets. For example, in data set A, the risk of culling was 9.0 times higher for the lowest-producing cows than for average producers (reference; Figure 3A). The corresponding values were much higher (15.1 and 17.3, respectively) in data sets B and C. On the other hand, the relative risk ratios for the highest-producing class were all between 0.5 and 0.6 for the 3 data sets, when compared with the average producers. Relative risk ratios for country of origin of sire (Figure $3 \mathrm{~B}$ ) showed marked differences between data sets. Compared with the class of daughters from Japanese sires used as reference in all data sets, the relative risk ratio for daughters of US sires was very low in data set C: the risk of being culled for daughters of American sires was $87 \%$ that of cows from Japanese sires. The relative risk ratio for a daughter of a Canadian sire was lower (93\%) than for cows of Japanese origin. On the other hand, a cow from a Canadian sire had a higher risk of being culled than a cow from a Japanese sire in data set A. These results underline that the effects of the country of origin of the sire on risk of being culled strongly differed over data sets. A cow having no type score in data set $\mathrm{C}$ had a 2.43 times higher risk of being culled than a cow with type score. The absence of a type score was also associated with an increase in risk of being culled in data set B (1.41).

Estimates of the gamma parameters, the associated herd-year variances, and the genetic parameters are reported in Table 2 for the 3 data sets. Estimates differed remarkably between data sets. The herd-year variance estimate for data set A was about twice the one of data set C. On the other hand, the largest sire variance was estimated in data set $\mathrm{C}$. As a result, the heritability for data set $\mathrm{C}$ was the largest (0.134) and about 3 times as large as the one for data set A (0.046).

\section{DISCUSSION}

The proportion of right-censored records in the 3 data sets considered here was low compared with other studies (Dürr et al., 1999; Caraviello et al., 2004; Ducrocq, 2005; Chirinos et al., 2007). This can be explained by a longer observation period considered. This is also reflected by large average failure times $(>1,100 \mathrm{~d})$. Dürr et al. (1999) and Caraviello et al. (2004) reported about 650 to $790 \mathrm{~d}$ of average time for censored and failure 
Table 2. Parameter estimates for the 3 data sets

\begin{tabular}{llll}
\hline & \multicolumn{3}{c}{ Data set } \\
\cline { 2 - 4 } Item & $\mathrm{A}$ & $\mathrm{B}$ & $\mathrm{C}$ \\
\hline Gamma parameter & 2.273 & 3.445 & 4.093 \\
Herd-year variance & 0.5504 & 0.3364 & 0.2766 \\
Sire variance & 0.0181 & 0.0348 & 0.0441 \\
$\mathrm{~h}^{2}{ }_{\text {eff }}$ & 0.046 & 0.102 & 0.134 \\
\hline
\end{tabular}

${ }^{1}$ Effective heritability (Yazdi et al., 2002).

records, respectively. Chirinos et al. (2007) had an average censoring time similar to this study, with a value of about 1,060 d in a Holstein-Friesian population in Basque Country, Spain. The longer observation period more clearly highlights differences between data sets.

Length of productive life appears to be largely dependent on the manager's decision. It is important to consider the management characteristics of each dairy herd when analyzing LPL. However, it is difficult to clearly categorize the management characteristics of each herd. In this study, the percentage of cows having type score was assumed to reflect at least partly different types of herd management characteristics. The results obtained for these 3 data sets suggest that the data set used by Terawaki et al. (2006), which was a subset of the data set $\mathrm{C}$ used here, corresponded to a part of Holstein herds in Hokkaido presenting particular (extreme) characteristics. Indeed, data set B included the larger part of all records, and data set A was representative of the other extreme of the range. The percentages of censored records and means of LPL were clearly different among data sets. Our results suggest that the proportion of cows having a type score is a potentially useful measure to represent herd management characteristics and goals in an analysis of LPL.

Differences in hazards between data sets were observed during the second stage of each lactation (60 to $250 \mathrm{~d}$ after calving). For this period, the hazard for cows in data set A was stable in first parity (Figure 1A) but gradually increased in the second (Figure 1B) and third parities (Figure 1C). The hazards during the second stage for data set $\mathrm{C}$ were stable in first (Figure $1 \mathrm{~A}$ ) and second parities (Figure 1B) and increased in third parity (Figure 1C). On the other hand, hazards on data set $\mathrm{B}$ were stable for all parities during this stage. These features of the hazards link with the fact that differences among the hazards of the 3 data sets get larger as parity and stage advanced. In a previous study (Terawaki et al., 2006), cut points for stage of lactation were found to strongly influence goodness of fit. The cut points used in this study were considered to be suitable regardless of parity and data set.
In the literature, models used for estimating genetic parameters of LPL usually do not include any factor related to herd management other than herd-year(-season). Recently, genetic analysis for LPL by region was reported. Garcia-Peniche et al. (2006) analyzed data on longevity traits collected from different regions over the United States and found a significant effect of regions on stayability. Caraviello et al. (2004) reported that heritability estimates of LPL, as well as estimates of the parameters of the Weibull distribution and the loggamma distribution of herd-year-season effects, differed among geographical regions, and they concluded that these differences, as well as differences in mean survival time and amount of censoring, were presumably due to regional variations in herd size, heat stress, housing facilities, and other management practices. Vukasinovic et al. (2001) found that Alpine pasturing seemed to have an extremely positive effect on longevity of Simmental cows. Buenger et al. (2001) indicated a significant effect of housing systems on LPL from Northwest Germany. Larroque and Ducrocq (2001) reported that effects of type traits on LPL were different between herd book
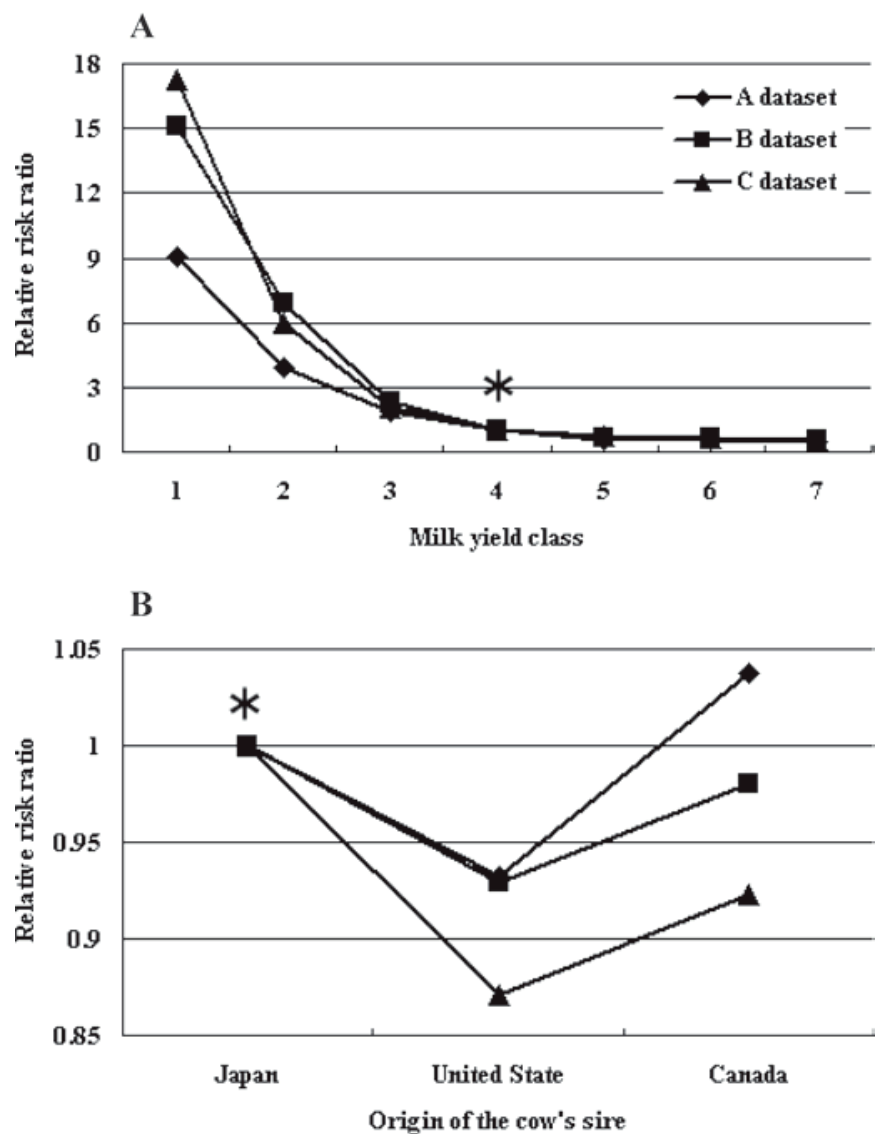

Figure 3. Relative risk ratios for milk yield and country of origin of the cow's sire for 3 data sets. An asterisk $(*)$ indicates reference group (set to 1). 
registered herds (UPRA) and other herds, not herd book registered (NON UPRA). The NON UPRA file had about $27.2 \%$ of cows that were typed. This would correspond to our B data set (18.6\%). Also, $68.9 \%$ of the cows in the UPRA file had type information. This file would correspond to our $\mathrm{C}$ data set $(77.4 \%)$. Relative risks of being culled of cows not scored were 2.15 and 1.17 in the UPRA and NON UPRA file, respectively. Comparing the results in Japan and France, it is clear that relationship between the percentage of type-scored cows and the effect of presence of a type score on LPL is similar in the 2 countries. Here, relative risk ratios of milk class, origin of the cow's sire, and presence of a type score were different across the data sets (Figure $3)$. It is assumed that at least part of these differences in relative risk ratios between data sets reflects differences of management policy among herds. The results suggest important disparities in the Hokkaido Holstein population on the relative emphasis given by the farmers to production traits and type traits. For example, the existence of dissimilarities in culling risk for cows with sires of different geographic origins may be at least related to differences in the relative importance of type traits in different countries (VanRaden, 2004; Miglior et al., 2005; AIPL, 2006; Shook, 2006; Canadian Dairy Network, 2008). Because Japan-NTP (Nippon Total Profit Index) was introduced in 1995, the relative emphasis in the breeding goal has been $75 \%$ on production and 25\% on type (Interbull, 2000; Kawahara, 2003). This indicates that the emphasis on production has been larger in Japan than in the United States and Canada for many years. This should be considered when interpreting the results on relative risk ratios by county of origin of sires.

Estimates of herd-year variances varied between data sets. Data set C included the smallest number of herds, and these herds were similar in size. The smaller estimate of herd-year variance (Table 2) indicates that the herds grouping by percentage of type-scored cows resulted in a data set $\mathrm{C}$ consisting of herds with similar management policy. On the other hand, data set A had very few records per herd compared with the other 2 data sets. The larger herd-year variance (Table 2) for data set A indicated that this data set might contain herds with diverse management policy. Caraviello et al. (2004) reported heritability estimates ranging from 0.05 to 0.13 (on the log scale) in differing geographical regions. Chirinos et al. (2007) estimated LPL heritability in 3 different regions representing different systems of production. The estimates ranged from 0.031 to 0.042 (i.e., were all somewhat similar to the one obtained for data set A). The heritability of LPL for French Holstein (0.108; Ducrocq, 2005) was similar to the one for our data set B. Sewalem et al. (2005) estimated the herita- bility of herd life in Canadian Holstein population on a lactation basis to be 0.14 (i.e., a value comparable to the highest one obtained in our study). Hence, the range of the 3 heritability estimates in this study was similar to the one observed over different countries. This fact indicates that the herds grouping in this study generated remarkably different data structures that play a role on genetic parameters and resulted in larger differences among genetic parameters than those reported by Caraviello et al. (2004) and Chirinos et al. (2007) across regions.

Consequently, the percentage of scored cows in each herd appears to be important to consider in the model for the genetic analysis of LPL of Holstein cows in Hokkaido.

\section{CONCLUSIONS}

The parameters estimated in this study showed features that are specific to each data set and that reveal factors related to herd management policy affecting LPL. Because each data set consisted of herds with a similar percentage of type-scored cows, this percentage was considered to at least partly characterize the management policy of each herd. The genetic parameters differed among the 3 data sets. Consequently, the consideration of the percentage of type-scored cows related to the herd management policy is important for the genetic analysis of LPL in the Holstein population in Japan.

\section{ACKNOWLEDGMENTS}

We thank Hokkaido Dairy Milk Recording and Testing Association (Hokkaido, Japan) for providing data for this study and the anonymous referees for contributing to the improvement of the manuscript.

\section{REFERENCES}

AIPL. 2006. Net merit as a measure of lifetime profit: 2006 revision. http://www.aipl.arsusda.gov/reference/nmcalc.htm Accessed Dec. 5, 2008.

Buenger, A., V. Ducrocq, and H. H. Swalve. 2001. Analysis of survival in dairy cows with supplementary data on type scores and housing systems from a region on northwest Germany. J. Dairy Sci. 84:1531-1541.

Canadian Dairy Network. 2008. Lifetime profit index (LPI) formula January 2008. http://www.cdn.ca/files_ge_articles.php Accessed Dec. 5, 2008.

Caraviello, D. Z., K. A. Weigel, and D. Gianola. 2004. Prediction of longevity breeding values for US Holstein sires using survival analysis methodology. J. Dairy Sci. 87:3518-3525.

Chirinos, Z., M. C. Carabaño, and D. Hernández. 2007. Genetic evaluation of length of productive life in the Spanish HolsteinFriesian population. Model validation and genetic parameters estimation. Livest. Sci. 106:120-131.

Ducrocq, V. 2005. An improved model for the French genetic evaluation of dairy bulls on length of productive life of their daughters. Anim. Sci. 80:249-256. 
Ducrocq, V., and J. Sölkner. 1998. The Survival Kit-V3.0: A package for large analyses of survival data. Proc. 6th World Cong. Genet. Appl. Livest. Prod. 27:447-448.

Dürr, J. W., H. G. Monardes, and R. I. Cue. 1999. Genetic analysis of herd life in Quebec Holsteins using Weibull models. J. Dairy Sci. 82:2503-2513.

Garcia-Peniche, T. B., B. G. Cassell, and I. Misztal. 2006. Effects of breed and region on longevity traits through five years of age in Brown Swiss, Holstein, and Jesery cows in the United States. J. Dairy Sci. 89:3672-3680.

Interbull. 2000. National genetic evaluation programmes for dairy production traits practiced in Interbull member countries 1999 2000. http://www-interbull.slu.se/bulletins/framesida-pub.htm Accessed Dec. 5, 2008.

Japan Dairy Council. 2007. A System of Voluntary Production Guidelines. http://www.dairy.co.jp/eng/eng07.cgi Accessed Dec. 5, 2008.

Kawahara, T. 2003. What's the news in NTP? (in Japanese). LIAJ News. No. 83. Livestock Improvement Association of Japan Inc., Tokyo.

Larroque, H., and V. Ducrocq. 2001. Relationships between type and longevity in the Holstein breed. Genet. Sel. Evol. 33:39-59.

LIAJ Inc. 2006. Milk recording report (in Japanese). Livestock Improvement Association of Japan Inc., Tokyo.

Mason, S. 2004. Longevity and burnout. http://www.agromedia.ca/ ADM_Articles/content/longburn.pdf Accessed Dec. 5, 2007.
Miglior, F., B. L. Muir, and J. Van Doormaal. 2005. Selection indices in Holstein cattle of various counties. J. Dairy Sci. 88:1255-1263.

Okada, N. 2001. Pages 27-30 in For prolonging longevity of dairy cows (in Japanese). Dairy Japan, Tokyo.

Röxström, A., V. Ducrocq, and E. Strandberg. 2003. Survival analysis of longevity in dairy cattle on a lactation basis. Genet. Sel. Evol. 35:305-318.

Sewalem, A., G. J. Kistemaker, V. Ducrocq, and B. J. Van Doormaal. 2005. Genetic analysis of herd life in Canadian dairy cattle on a lactation basis using a Weibull proportional hazards model. J. Dairy Sci. 88:368-375.

Shook, G. E. 2006. Major advances in determining appropriate selection goals. J. Dairy Sci. 89:1349-1361.

Terawaki, Y., T. Katsumi, and V. Ducrocq. 2006. Development of a survival model with piecewise Weibull baselines for the analysis of length of productive life of Holstein cows in Japan. J. Dairy Sci. 89:4058-4065.

VanRaden, P. M. 2004. Invited review: Selection on net merit to improve lifetime profit. J. Dairy Sci. 87:3125-3131.

Vukasinovic, N., J. Moll, and L. Casanova. 2001. Implementation of a routine genetic evaluation for longevity based on survival analysis techniques in dairy cattle populations in Switzerland. J. Dairy Sci. 84:2073-2080.

Yazdi, M. H., P. M. Visscher, V. Ducrocq, and R. Thompson. 2002. Heritability, reliability of genetic evaluations and response to selection in proportional hazard models. J. Dairy Sci. 85:15631577 . 